\title{
Dependence structures between Sovereign credit default swaps and global risk factors in BRICS countries
}

Prayer Rikhotso $^{*}$ and Beatrice D. Simo-Kengne ${ }^{\dagger}$

\begin{abstract}
.
This study examined the tail dependency structure of sovereign credit risk and three global risk factors in BRICS countries using copulas approach, which is known for its ability to provide the "true" tail correlation based on the correct marginal distribution. The empirical results show that global market risk sentiment comoves with sovereign CDS spreads across BRICS countries under extreme market events, with Brazil having the highest co-dependency followed by China, Russia, and South Africa. Furthermore, oil price volatility is the second biggest risk factor correlated with sovereign CDS spreads for Brazil and South Africa while exchange rate risk exhibits very small co-dependence with sovereign CDS spreads under extreme market conditions dominated by tail events. On the contrary, exchange rate risk is the second largest risk factor co-moving with China and Russia’s sovereign CDS spreads while oil price volatility exhibits the lowest co-dependence to CDS in these countries. Between oil price and currency risk, evidence of single risk factor dominance is found for Russia where exchange rate risk is largely dominant. These results suggest that BRICS policymakers might consider financial sector regulations that mitigate risks spill-over such as targeted capital controls when markets are distressed.
\end{abstract}

Keywords: Global risk factors, Credit Default Swaps, Sovereign credit risk, Copulas approach

JEL classification: C46, F36, G11, G15

\footnotetext{
* School of Economics, University of Johannesburg

† Corresponding author. School of Economics, University of Johannesburg, Email. bdsimo-kengne@uj.ac.za
} 


\section{Introduction}

BRICS economies enjoyed a significant rise (i.e., quadrupled) in foreign investment inflows in the last 20 years as global investors diversify away risk and pursue investments with higher yields, resulting in net portfolio inflows peaking at \$US 55.5bn in 2019, up from \$US 12.3bn in 2009 (World Bank, 2021). The continued deepening of bilateral and intergroup trade cooperation has ultimately resulted in inseparable interdependence across various macroeconomic fundamentals such as external account balances, GDP, portfolio investments, FX liquidity reserves, interest rate spreads, foreign direct investment (FDI) and sovereign credit risk. Among others, these fundamentals are key drivers of sovereign credit risk commonly measured by sovereign CDS spreads (Yang, Yang, and Hamori, 2018; Wisniewski \& Lambe, 2015).

The first quarter (Q1) of 2020 witnessed a simultaneous and sudden spike in sovereign CDS spreads for all BRICS economies which coincided with the global oil price shocks and outbreak of Coronavirus pandemic, collectively amplifying negative global economic outlook and bearish market sentiments. At this time, sovereign CDS spreads for all BRICS countries overshot to all-time highs (as much as 450 basis points for South Africa), exacerbated by noise traders executing knee-jerk reactionary trades ordering mass disposal of emerging market bonds in their global portfolios. Investors hoarding their risky portfolios demanded a higher premium for holding emerging market risk, such as BRICS sovereign bonds, leading to an increase in the CDS spreads, which indicates the heightened cost of insuring against sovereign default risk. Therefore, understanding the dependence structure between CDS spreads and global risk factors becomes vital for the financial stability.

In the literature, dependence structure analysis is gounded on financial contagion or co-movement theory, which offers several reasons for convergence in financial returns and associated risk measures (Yang, Yang, \& Hamori, 2018; Ballester \& Gonzalez-Urteaga, 2020; Boubaker \& Sghaier, 2013; Galariotis, Makrichoriti, \& Spyroub, 2016). Based on this theory, financial returns converge in line with fundamentals as well as coordinated traders' behaviour, causing sustained aggregate demand shifts in the financial markets, ultimately resulting in co-movements in fundamentally unrelated risk measures (Aas, 2004). This, theory predicts that, as aggregate demand in emerging market sovereign bonds gains bearish momentum during periods of elevated global risks, the sovereign CDS spreads ultimately rise (implying weakening credit risk profile), resulting in evident negative co-movements between sovereign CDS and global risk sentiments (Pindyck \& Rotemberg, 1990; Barberis \& Shleifer, 2003). Similarly, stronger codependencies are predicted for CDS and other global risks like oil price volatility and exchange rate risk. 
Existing literature follows two distinct but related approaches in studying sovereign CDS and global risks factors, one assumes exogeneity while the other approach relies on endogeneity of CDS spreads. The first focuses on the contagion effects of CDS risks on domestic market and macroeconomic fundamentals (Park, Kutan \& Ryu, 2019; Hui \& Fong, 2015). Accordingly, Grammatikos and Vermeulen (2012) reported significant transmission of sovereign debt crisis shocks onto the European financial sector stock returns and exchange rates, a finding which is common in literature (Wang, Yang \& Yang, 2013; Ballester \& Gonzalez-Urteaga, 2020). However, this approach is criticised for ignoring the indisputable impact of universal access to global financial markets which is the conduit for colossal financial shockwaves in the debt capital markets (ultimately, amplifying volatility in the domestic financial markets) during stressed macroeconomic conditions such as the global financial crisis (Hui \& Fong, 2015; Park, Kutan \& Ryu, 2019).

The second approach considers sovereign CDS spreads as endogenous factor and investigates the impact of various global risk factors on sovereign credit risk (Gorzo, Lazcano, Márquez, Gismera \& Lumbreras, 2020). Global risk factors are exogenous in nature and empirical evidence attests that the sovereign risk profile of emerging economies is demonstrably and evidently vulnerable to global shocks (Augustin, Chernov \& Song, 2020; Naifar, 2020; Grammatikos \& Vermeulen, 2012). Therefore, the exogeneity assumption often fails empirical rigour, particularly in emerging markets where sovereign CDSs exhibit extreme volatility during periods of bearish global risk sentiment and catastrophic risk events like a global financial crisis and global coronavirus pandemic (Kartal, 2020; Augustin, Chernov \& Song, 2020; Dopierala, Ilczuk \& Wojciechowski, 2020).

Recent empirical studies apply the theory of co-movements to investigate the relationship between risk factors, arguing that co-movements found in asset returns also occur across risk variables (Guo, Han, Liang, Ryu \& Yu, 2020; Hassan, Kayhan \& Bayat, 2016; Hui \& Fong, 2015; Wang, Yang \& Yang, 2013). Choe, Choi and Jang (2020) recently examined systemic risk spillovers into sovereign CDSs and focused on contagion effect, reporting evidence of contagion risk and simultaneity during the European sovereign debt crisis and global financial crisis events. An Asian region-focused study documented evidence of comovements in sovereign CDS spreads across Asian countries and major sub-regions, a result which is widely reported in literature across developed and emerging markets (Guo, Han, Liang, Ryu \& Yu, 2020; Hassan, Kayhan \& Bayat, 2016; Hui \& Fong, 2015). 
This study builds upon the foundations laid by extant literature and analyse co-movements across several risk factors such as the sovereign credit risk and other global risk factors including oil price risk, risk sentiment and exchange rate volatility. From a BRICS perspective, sovereign CDS literature is limited to examining how sovereign risk determinants compare between BRICS and developed economies but bivariate risk factor co-dependence has been given limited attention. The recent study by Yang, Yang \& Hamori (2018) broadly examines core determinants of CDS risk and how risk factor intensity compare between BRICS and G7 economies and they found strong Granger causality between sovereign CDS risk, and exchange rates and oil price risk. These findings complement non-parametric studies based on copula techniques, which report co-movement between sovereign CDS spreads and exchange rate and/or oil price risk across developed and emerging markets. Particularly, Yang, Yang \& Hamori (2018) investigated the dependence structure of sovereign CDS and oil price volatility in BRICS and G7 countries using copula with wavelet analysis and found evidence of simultaneous co-movements during economic prosperity but divergence was evident during macroeconomic downturns.

The above studies pioneered non-parametric analysis of sovereign CDS and other global risks in the BRICS context but they focused on analysing how global risks drive sovereign CDS volatility, with sovereign CDS presumed to be endogenously determined. These studies provide insights on how global risk factors influence sovereign credit risk for BRICS economies, however, they are silent on whether the impact of such global determinants is homogenous within and across BRICS countries. If one considers the deterministic effects of global risks on sovereign CDS (i.e., another global risk factor), these risk factors could be correlated overtime. If bivariate co-dependence exists, the nature of bilateral comovement between sovereign risk and other global risk drivers is crucial to consider, particularly because a heterogeneous block of countries could exhibit varying bivariate co-movement patterns, which must be considered when formulating joint macroeconomic policies to advance the shared economic aspirations to compete in the global trade arena.

In addition, very few studies analyse convergence between these risks while many papers use several risk factors to explain one key risk, particularly sovereign credit risk whose determinants are likely to exhibit some bivariate pairwise correlation, in addition to explaining variability observed in CDS spreads (Aas, 2004). Building on the deterministic relationship of oil price risk, global market sentiment, and currency volatility on sovereign CDS risk, this study investigates whether the bilateral pairwise co-movements between individual global risks and sovereign CDS converge over time. This study seeks to provide cross- 
and within-country comparison of the dependence structures between individual global risk factors and sovereign CDS spreads in BRICS. The rest of this study will be structured as follows; section 2 presents the data and methodology, section 4 discusses the empirical results, while section 5 concludes with some policy implications.

\section{Materials and Methods}

\subsection{Data description, transformations, and visual inspections}

\section{Data scoping, collection frequency and transformations}

This empirical study uses daily observations sourced from Thomson Reuters of the Brent crude oil price, global equity market volatility index, local exchange rates against US Dollar, and sovereign CDS spreads data collected over five years from 21 March 2016 to 18 March 2021. The sovereign CDS spreads and exchange rates for Brazil, Russia, China, and South Africa were collected for further analysis but India was excluded due to limited availability of data on sovereign CDS spreads. Most importantly, the scope of analysis is aligned to the maturity profile of the sovereign CDS contracts (up to five years maturity), which represents the highly liquid and most actively traded sovereign CDSs in the secondary market, thereby allowing for the collection of high-frequency data or daily observations for all variables. This scope is consistent with many leading papers that examined the dependence structure of sovereign CDSs and other risk factors across many developed and developing markets (Wang, Sun \& Li, 2020; Lahiani, Hammoudeh \& Gupta, 2016; Pavlova, de Boyrie \& Parhizgari, 2018).

All data collected was converted into daily returns which are stationary, with the augmented Dickey-Fuller (ADF) tests confirming the absence of unit roots. The daily returns are calculated using the natural logarithm of today's closing price divided by the closing price of the previous day, formally represented by the below function:

$$
r_{t}=\ln \left(\frac{P_{t}}{P_{t-1}}\right) \quad \text { or } \quad r_{t}=\ln \left(\frac{\text { Index }_{t}}{\text { Index }_{t-1}}\right)
$$

Where $P_{t}$ is the daily closing price of Brent crude oil, exchange rate and sovereign CDS spread while Index $_{t}$ is the closing level of global equity market volatility and $r_{t}$ represents the daily logarithmic changes in each variable collated for further descriptive analysis, and results are summarised in Table A.

The daily changes in sovereign CDS spreads are used as a proxy for sovereign credit risk, implying that huge spikes in sovereign CDS spreads are indicative of increased riskiness of sovereign assets as CDS 
providers demand higher risk premia (or high spreads) to compensate for perceived incremental default risks on the underlying sovereign credit obligations to the investors. Global market risk sentiment is extracted from daily changes in global equity market volatility index. Furthermore, daily changes in exchange rates and Brent crude oil price are collated and used as inputs to extract daily volatility of oil price and exchange rates against the US Dollar by fitting appropriate generalised autoregressive conditional heteroskedasticity (GARCH) processes.

The daily volatilities extracted from GARCH models are used as the daily observations of exchange rate risk and oil price risk over the five year while sovereign CDS and global risk sentiment will be analysed using daily returns, not daily volatility. Before fitting the GARCH process to model volatility, we fit a standard autoregressive moving average with one lag (i.e., ARMA $(1,1)$ ) as mean model and GARCH $(1,1)$ with one lag as a variance model as GARCH process specification. To extract the daily volatility, we fitted the ARMA $(1,1)$ GARCH $(1,1)$ model with standard GARCH and exponential GARCH processes to determine if there are symmetrical effects of previous volatility on present-day observations and plotted the QQ plot and News Impact Curve for further visual inspection before conducting goodness of fit tests. The fitted ARMA $(1,1)$ GARCH $(1,1)$ model is defined below:

$$
\begin{aligned}
& r_{t}=\alpha_{0}+\phi r_{t-1}+\theta \varepsilon_{t-1}+\varepsilon_{t} \\
& \sigma_{t}^{2}=\alpha_{0}+\alpha_{1} \varepsilon_{t-1}^{2}+\beta \sigma_{t-1}^{2}+\Upsilon_{1} I_{t-1} \varepsilon_{t-1}^{2}
\end{aligned}
$$

where: $I_{t-1}=\left\{\begin{array}{l}1 \text { if } \varepsilon_{t-1}<0 \\ 0 \text { if } \varepsilon_{t-1} \geq 0\end{array}\right.$

Where the $r_{t}$ is the mean model and $\sigma_{t}^{2}$ is the estimated variance of the empirical data which is represented by the residuals from fitted GARCH models. The variance series represents daily volatility in the exchange rates and oil price, which is the measure of oil price risk and currency risk, for this study.

\section{Visual inspection of daily volatilities and changes in CDS and global risks.}

For this study, changes in sovereign CDS spreads are used as proxy for sovereign credit risk profile, implying that huge spikes in sovereign CDS spreads implies increased riskiness of sovereign assets as CDS providers demand higher risk premia (or high spreads) to compensate for perceived incremental default risks on the sovereign credit obligations held by investors. Global market risk sentiment is 
observed from changes in the global volatility index as represented by logarithmic changes in the Chicago Board of Exchange equity volatility index (VIX). Furthermore, the logarithmic changes in the exchange rates and oil price were used as inputs to extract daily volatility by fitting appropriate generalised autoregressive conditional heteroskedasticity (GARCH) processes to extract daily volatility for Brent crude oil prices and each local currency against the US Dollar.

Volatility clusters are appearing around the same time in the return's series and notably large volatility clustering prevailed in Q1 2020 when massive global oil price shocks occurred, signifying that sovereign CDS spreads spiked to record highs during the oil price shock events, and changes in global risk sentiment also peaked to highest levels when global oil price plummeted to record lows, see figure 4. Volatility is modelled using GARCH processes which considers the time-varying and autocorrelated nature of residuals series over time, which are attributes characterising exchange rate and oil price history (see visual presentations and GARCH tests). Accordingly, the GARCH process will be used to extract daily

volatility (variance) and copulas will be used to assess the underlying dependence structures and compare that against linear correlation coefficients, which presupposes that empirical financial data follow elliptical distributions.

The GARCH models extracted daily volatility for oil price and exchange rates which is used for further analysis of dependence structure, with results summarised in Tables B and C. Key observations from the fitted GARCH models exhibit strong evidence of asymmetric impact of historical shocks on present-day volatility of oil prices and exchange rates, with the empirical results confirming that the exponential (eGARCH) term is statistically significant in modelling exchange rates and Brent crude oil price risks. Hence, this evidence indicates that positive historical oil price shocks have higher effects than negative shocks on the present-day volatility, which means the impact is asymmetrical, (Longin \& Solnik, 2001).

\subsection{Copulas theory and applications in financial econometrics}

The correlated movements of financial variables are widely studied in empirical literature, with many studies often analysing dependence structure using simple correlation and other linear measures, which hinge on the assumption of normal distribution (Aas, 2004). However, the normality of financial returns data lacks empirical rigour, therefore, any statistical inference drawn remains questionable (Ballester \& Gonzalez-Urteaga, 2020; Lahiani, Hammoudeh, \& Gupta, 2016). Against this backdrop, several nonparametric techniques have been developed and utilised in recent literature, and copulas have gained strong research utility in financial econometrics (Blum, Dias, \& Embrechts, 2002). 
A Copula C can be defined as a function linking univariate marginal distributions to the joint multivariate distribution functions of at least two random variables and permit further decomposition of any ndimensional joint distribution into its marginals, thereby allowing for accurate description of joint distributions without relying on the assumption of distributional normality (Aas, 2004). Copula theory gains more popularity among researchers for the capability to simultaneously extract dependence structure from the joint probability distribution function and isolate such dependence structure from univariate marginals (Boubaker \& Sghaier, 2013). Copulas overcome the restrictive assumption of normality in financial time series and are often used in empirical research (Bouye et al., 2000; Embrechts, McNeil, \& Straumann, 2002; Embrechts, Lindskog, \& McNeil, 2001; Lindskog et al., 2003).

Formally, we define Copula $\mathrm{C}$ as an $\mathrm{n}$-dimensional random vector $x=\left(x_{1}, x_{2}\right)$ for two dimensions ( $\mathrm{n}=$ 2), with joint distribution function $F=\left(x_{1}, x_{2}\right)$ and marginal distributions $F_{i}\left(x_{i}\right)$ where the subscript $i=$ 1, 2. Given this construct, Sklar's theorem states that there exists a copula $C\left(u_{1}, u_{2}\right)$ such that:

$$
F\left(x_{1}, x_{2}\right)=P\left(X_{1}<x_{1}, X_{2}<x_{2}\right)=C\left(F_{1}\left(x_{1}\right), F_{2}\left(x_{2}\right)\right)
$$

If $F_{i}$ are continuous, then the copula $C\left(u_{1}, u_{2}\right)$ is unique. Copulas permit different degrees of tail dependence, the upper and the lower tail dependence, which are expressed formally as follows:

$$
\begin{aligned}
& \lambda_{U}=\lim _{U \rightarrow 1^{-}} P\left(U_{1}>u \mid U_{2}>u\right)=\lim _{U \rightarrow 1^{-}} \frac{C^{*}(u, u)}{1-u} \\
& \lambda_{L}=\lim _{U \rightarrow 0^{+}} P\left(U_{1}<u \mid U_{2}<u\right)=\lim _{U \rightarrow 0^{+}} \frac{C(u, u)}{u}
\end{aligned}
$$

$C^{*}$ is referred to as the survival copula.

Therefore, copula can be interpreted as a function linking the marginal distributions of a random vector to its joint distribution (Fang \& Fang, 2002). There exist many types of dependence structures to estimate the joint marginal distributions but for simplicity, we present fivee dependence structures from the Archimedean family which are found to be more common in this empirical study - see sub-section 3.2.2.

\section{Optimal Copulas using Vine-Copula package}

The daily residuals for oil price and exchange rate, and changes in global volatility (VIX) are merged with the sovereign CDS spread changes and used as inputs into the bivariate Vine-Copula process to best select the most optimal copula family type for each bivariate pair of sovereign CDS and each global risk. The 
optimal copula types are deduced from the Vine-Copula package and then fitted into the empirical data for further analysis of tail dependence structures and estimate co-dependency parameters for each bivariate sovereign CDS and risk factor combination. According to Aas (2004), the best-fit copula type is given by minimising the distance of empirical copula of the data, where empirical copula $\left(C_{e}\right)$ is given by:

$$
C_{e}\left(u_{1}, u_{d}\right)=\frac{1}{n} \sum_{1=1}^{n} \prod_{j=1}^{d} I\left(\bigcup_{i, j}<u_{j}\right)
$$

and the optimal minimisation function is defined by:

$$
\operatorname{distance}\left(C, C_{e}\right)=\sqrt{\sum_{i=1}^{n} \sum_{d=1}^{n}\left(C\left(\frac{i_{1}}{n},,,, \frac{i_{2}}{n}\right)-C_{e}\left(\frac{i_{1}}{n},,,, \frac{i_{2}}{n}\right)\right)^{2}}
$$

The Vine-Copula packages solve this optimisation problem defined by equation (8) and the ultimate optimal copula family is chosen using the Akaike and Bayesian Information Criteria (AIC and BIC, respectively), with the selection criteria formally defined and represented below:

For observations $u(i, j), i=1, \ldots \ldots \ldots \ldots N, j=1, \ldots \ldots \ldots \ldots$, the AIC of a bivariate copula family $C^{N}$ with parameter(s) $\{\boldsymbol{\theta}\}$ is defined as:

$$
A I C=-2 \sum\left\{i=1^{\wedge} N \mid \ln [c(u(i, 1), u(i, 2) \mid \boldsymbol{\theta}]+2 k\}\right.
$$

where $k=1$ for one parameter copulas and $k=2$ for the two parameters copula.

Similarly, the BIC is obtained by:

$$
B I C=-2 \sum\left\{i=1^{\wedge} N \mid \ln [c(u(i, 1), u(i, 2) \mid \boldsymbol{\theta}]+\ln (N) k\}\right.
$$

Firstly, all available copulas are fitted using maximum likelihood estimation. Then the criteria are computed for all available copula families and the family with the minimum value is chosen. Evidently, if the BIC is chosen, the penalty for two-parameter families is stronger than when using the AIC.

\section{Pairwise tail-dependence of sovereign CDS and global risks}

Considering the overwhelming statistical evidence showing that distributional normality assumption does not hold for BRICS, as affirmed by J-B goodness of fit tests, we avoid drawing statistical inference based on measures of association assuming normality such as Spearman linear correlation coefficient. Therefore, this study deploys copulas approach, which consistently gains research popularity to measure dependence structure, as copulas can identify true underlying distributional properties of the empirical data set (Blum, 
Dias, \& Embrechts, 2002). Copulas are appealing in modelling financial returns because of their strong capability to examine the skewness and kurtosis to detect the underlying distribution of empirical data (Bouye, Durrlemann, Nikeghbali, Riboulet, \& Roncalli, 2000).

In this study, we use copulas to investigate tail dependence structures, which allows for extrapolation of co-movements in sovereign CDS and global risks when extreme market volatility or tail events occur. Optimal copulas are fitted to each bivariate empirical combination to extract tail dependence structures, with results summarised in Table $\boldsymbol{C}$ under section 4.3 of results discussion. Below, we formally present Archimedean and elliptical copulas relevant to this study. Gaussian and Frank types are the elliptical copulas while Clayton and Gumbel are asymmetrical and exhibit greater tail dependence on the upper and lower tail ends of the distribution, capturing asymmetries.

\section{o Gaussian Copula}

Gaussian copula is symmetrical with negative and positive tail dependence netting each other off to zero, which is formally defined as follows:

$$
C_{\rho}\left(u_{1}, u_{2}\right)=\int_{-\infty}^{\phi_{u_{1}}^{-1}\left(u_{1}\right)} \int_{-\infty}^{\phi u_{1}^{-1}\left(u_{2}\right)} \frac{1}{2 \pi} \frac{1}{\sqrt{1-\rho^{2}}} \exp \left\{-\frac{x^{2}-2 \rho x y+y^{2}}{2\left(1-\rho^{2}\right)}\right\} d x d y
$$

Where $\rho$ is the copula parameter and $\phi^{-1}($.$) represents the inverse of the standard univariate normal$ distribution function with a mean of zero and variance of one.

The coefficients of the upper and lower tail dependence are given by:

$$
\lambda_{\mathbb{L}}(\mathrm{X}, \Upsilon)=\lambda_{\mathbb{U}}(\mathrm{X}, \Upsilon)=2 \lim _{x \rightarrow \infty} \phi\left(1+\frac{\sqrt{1-\rho}}{\sqrt{1+\rho}}\right)=0
$$

Due to symmetry, twice the sum of positive and negative tail events equals zero for Gaussian copula. This means that even if the correlation is very high, the extreme tail events occur independently and the variables do not exhibit co-movements over time (Aas, 2004).

\section{o Frank Copula}

Frank copula is symmetrical and behaves like Gaussian copula by netting off positive and negative tail dependence to zero, which is formally defined as follows: 


$$
C_{F}\left(u_{1}, u_{2}\right)=-\frac{1}{\theta} \ln \left(1+\frac{\left(e^{\theta u_{1}}-1\right)\left(e^{\theta u_{2}}-1\right)}{e^{-\theta}-1}\right)
$$

The generator is given by:

$$
\phi(t)=-\ln \left(\frac{e^{-\theta t}-1}{e^{-e}-1}\right), \text { where } \theta \neq 1
$$

Both the positive and negative dependence are equal to zero because they are symmetrical. In this instance, a stronger linear correlation does not imply tail dependence. If tail events are observed, then the extreme observations occur independently of each other (Aas, 2004).

\section{O Student-t Copula}

Student-t copula, unlike Gaussian and Frank type, can account for joint fat tails in the distribution function and increased probability of joint extreme events, which makes it superior to the Gaussian or the elliptical copula family, in general. Formally, Student-t copula is defined as follows.

$$
C_{\rho, v}\left(u_{1}, u_{2}\right)=\int_{-\infty}^{t u_{1}^{-1}\left(u_{1}\right)} \int_{-\infty}^{t_{u_{1}}^{-1}\left(u_{2}\right)} \frac{1}{2 \pi} \frac{1}{\sqrt{1-\rho^{2}}}\left\{1+\frac{x^{2}-2 \rho x y+y^{2}}{v\left(1-\rho^{2}\right)}\right\} d s d t
$$

Where $\boldsymbol{\rho}$ and $\boldsymbol{v}$ are parameters of Student-t copula and $\boldsymbol{t}_{\boldsymbol{v}}^{-\mathbf{1}}$ is the inverse of the standard univariate Studentt distribution with $\boldsymbol{v}$ degrees of freedom, statistical mean of zero and variance defined by $\frac{\boldsymbol{v}}{\boldsymbol{v}-\mathbf{2}}$. Student-t copula has degrees of freedom $\boldsymbol{v}$ parameter, such that, when $\boldsymbol{v}$ increases, the tendency of extreme codependency decreases. The dependence coefficients of upper and lower tails are given by:

$$
\lambda_{\mathbb{L}}(\mathrm{X}, \Upsilon)=\lambda_{\mathbb{U}}(\mathrm{X}, \Upsilon)=2 t_{v+1} \phi\left(\sqrt{1+\rho}\left(\frac{\sqrt{1-\rho}}{\sqrt{1+\rho}}\right)\right)
$$

Whereby $\boldsymbol{t}_{\boldsymbol{v}+\mathbf{1}}$ is the distribution function of a univariate Student-t distribution with $\boldsymbol{v}+\mathbf{1}$ degrees of freedom. For higher linear correlation $\boldsymbol{\rho}$, the degrees of freedom $\boldsymbol{v}$ will be smaller and the tail dependence will be stronger. Most importantly, Student-t copula denotes asymptotic tail dependence when linear correlation coefficient $\boldsymbol{\rho}$ is negative and/or zero. 


\section{o Clayton Copula}

It is an asymmetric Archimedean and exhibits greater dependence on the negative tails than it does in the positive tails. It is formally expressed by:

$$
C_{c}\left(u_{1}, u_{2}\right)=\max \left[\left(u_{1}^{-\theta}+u_{2}^{-\theta}-1\right)^{-\theta^{-1}}, 0\right]
$$

and the generator is given by:

$$
\phi(t)=\theta^{-1}\left(t^{-\theta}-1\right) \text {, where } \theta \epsilon[-1,+\infty[\backslash\{0\}]
$$

The positive (upper tail, $U_{C}$ ) and negative (lower tail, $L_{C}$ ) tail dependence are given by:

$$
\lambda_{u_{c}}=0 \text { and } \lambda_{L_{c}}=2^{-\theta^{-1}}
$$

Clayton copula captures co-dependency for extreme lower tail events and accounts for asymmetry which Student-t copula does not allow, due to restrictive parameters under Student-t copula.

\section{O Gumbel Copula}

It is also an asymmetric Archimedean but different from Clayton in that it exhibits a greater dependence in the upper tail than the lower tail. It is formally expressed by:

$$
C_{G}\left(u_{1}, u_{2}\right)=\exp \left(-\left[-\ln \left(u_{i}\right)^{\theta}+\left(-\ln \left(u_{2}\right)\right)^{\theta}\right]^{\theta^{-1}}\right)
$$

The generator is given by the following:

$$
\phi(t)=(-\ln (t))^{\theta}, \text { where } \theta \geq 1
$$

The positive (upper tail, $U_{G}$ ) and negative (lower tail, $L_{G}$ ) tail dependence are given by:

$$
\lambda_{U_{G}}=2-2^{-\theta} \text { and } \lambda_{L_{G}}=0
$$

Gumbel copula captures co-dependency for extreme lower tail events and accounts for asymmetry which Student-t copula does not accommodate, due to the restrictive parameters thereon. 


\section{Results discussion and interpretation}

\subsection{Exploratory analysis of daily returns structure}

Table A: Descriptive Statistics

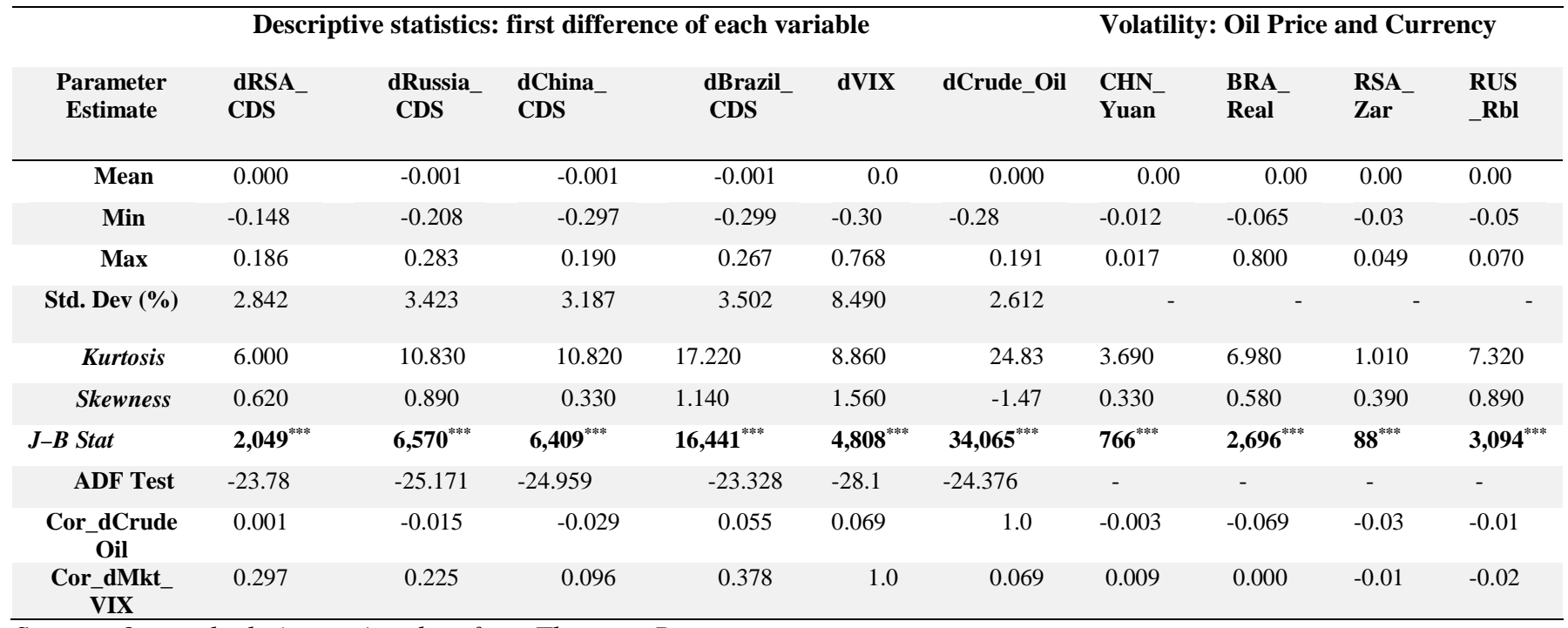

Source: Own calculations using data from Thomson Reuters. *** Statistically significant results at $1 \%$ level

Skewness and kurtosis are crucial measures that determine whether the empirical data is normally distributed or non-normal, which is important to ascertain before analysing correlation measures which presuppose that underlying data is normally distributed. Skewness measures whether the distribution of data is symmetrical or asymmetrical, which is the overarching quality of normally distributed random variables. The values for skewness between -0.5 and +0.5 are considered acceptable to prove normal univariate distribution while skewness greater than +1 or less than -1 depicts highly skewed empirical data (George \& Mallery, 2010; Hair et al., 2017, p 61). Kurtosis measures whether the distribution of empirical data is too peaked or too flat and kurtosis below - 1 indicates too flat distribution while kurtosis greater than +1 indicates highly peaked distributions, implying that such heavily peaked or too flat distributions are not normal (Hair et al., 2017, p 61). Kurtosis and skewness measured outside the above guidelines represent empirical data that is not normally distributed and Jarque-Bera (J-B) goodness of fit tests are useful to determine if the kurtosis and skewness fit within normal distribution parameters.

The changes in sovereign CDSs for South Africa, Russia and China are symmetrical while Brazil is heavily skewed to the right. Changes in global risk sentiment and crude oil price are heavily skewed, signifying that tail events are dominant, and the data may not be normally distributed. The kurtosis measure is greater than +1 for all variables, which is evidence of heavily peaked distribution that violates 
the properties of normal distribution. The kurtosis and asymmetry measures for BRICS and global risk factors are not consistent with normal distribution properties.

The J-B goodness of fit test is conducted to conclusively determine if the empirical data is normally distributed. The J-B test statistics are positive, and it is close to zero for normally distributed data. That is, the further away it is from zero, the stronger the evidence that empirical data is not normally distributed. The J-B test statistic for BRICS is extremely high and p-value is 0.00 , thus reaffirming that the empirical data is not normally distributed.

Considering this evidence, it is not appropriate to analyse the dependency structure of sovereign CDSs and global risk factors using measures of association that assume distributional normality such as Spearman correlation coefficient. Hence, we need to analyse the dependency structure considering the underlying distributional properties of each variable and their combined marginal distributions, and this outcome is best achieved by using copulas to simultaneously decompose univariate dependence structures and link the marginals to the joint distributions without prior assumption on the univariate distribution. In this study, we analyse association and contrast the dependence structures of sovereign CDSs and global risk factors using both Spearman correlation coefficient and rank dependent measures on “distributioncorrected data” obtained from copulas and show that copula-based results are more robust and reliable than simple Spearman correlation measure.

As shown in Table A, changes in sovereign CDS spreads were broadly negative and almost negligible on average terms, however, focusing on average changes overlooks the inherently persistent volatility in the spreads as evidenced by massive variance between the day's minimum and maximum intraday spreads. To this end, the standard deviation provides more accurate indication of the realised volatility, which ranges from 2.84\% to 3.5\% for the group understudy, with Brazil recording the highest volatility of 3.5\% while South African had the lowest at $2.84 \%$.

The standard deviation of oil prices and sovereign CDS spreads is much higher in the 2020-2021 period possibly because of several shocks that occurred including the global oil price shocks in 2020 and deterioration in global market sentiment due to the coronavirus outbreak, among others risks, resulting in abrupt adverse changes (i.e., deterioration) in sovereign credit risk profile of emerging markets. The standard deviation of global risk sentiment was the highest at 8.5\% and oil price changes averaged 2.6\%. The augmented Dickey-Fuller (ADF Test) confirms stationarity at first difference at $0.1 \%$ significance 
level, which satisfies the necessary and required conditions to apply GARCH processes to model volatility of the exchange rates and oil price series.

\subsection{Linear dependence structures - simple linear correlation measure.}

Table B: Spearman correlation of sovereign CDSs and risk factors

\begin{tabular}{|c|c|c|c|c|c|c|c|}
\hline \multicolumn{8}{|c|}{ Linear Correlation Matrix: Spearman measure of association for Sovereign CDS spreads and; } \\
\hline & \multicolumn{3}{|c|}{ Daily Log Changes } & \multicolumn{4}{|c|}{ Daily Volatility of Oil Price and Exchange Rate } \\
\hline & dVIX & dCrude_Oil & Crude_Oil & CHN_Yuan & BRA_Real & RSA_Zar & RUS_Rbl \\
\hline dRSA_CDS & 0.297 & 0.001 & 0.004 & - & - & -0.018 & - \\
\hline dRussia_CDS & 0.225 & -0.015 & -0.012 & - & - & - & 0.154 \\
\hline dChina_CDS & 0.096 & -0.029 & -0.027 & 0.026 & - & - & - \\
\hline dBrazil_CDS & 0.378 & 0.055 & 0.058 & & -0.042 & - & - \\
\hline Corr_dCrudeOil & 0.069 & 1.0 & 1 & -0.003 & -0.069 & -0.033 & -0.058 \\
\hline Corr_dMkt_VIX & 1.0 & 0.069 & 0.069 & 0.009 & 0.000 & -0.010 & -0.330 \\
\hline
\end{tabular}

Source: Own calculations using data from Thomson Reuters

The Spearman correlation between crude oil price risk and sovereign CDS spreads differs across countries, showing very weak and negligible positive association for South Africa (0.4\%) while Brazil has the highest correlation of 5.8\% given the high consumption as a net importer of oil. Similarly, oil price risk exerts negative influence on Russian and Chinese sovereign CDS spreads, with China's credit risk being the worst negatively impacted compared to Russia’s credit risk profile. Similarly, the correlation between sovereign CDS and global risk sentiment is positive across all countries under review but strong and more pronounced for Brazil (38\%) and South Africa (30\%) while it is the weakest for China (10\%). This means that positive global markets news is associated with noticeable improvement in credit risk spreads for BRICS sovereign bonds and the opposite is true for deterioration in global market risk sentiment. This observation is consistent with previous studies which documented similar results for BRICS countries which are crucial emerging markets that are integral to global economic architecture.

Most importantly, changes in global risk sentiment affect sovereign credit risk more than oil price risk for BRICS economies, which is exacerbated by temporary but colossal portfolio outflows fueled by knee-jerk large-scale disposals of higher-yield emerging markets sovereign bonds and migrating funds into haven investment instruments such as US treasury bills during the period of heightened uncertainty. The correlation strength between exchange rate risk and sovereign CDS is generally weak across but negative for South Africa and Brazil while it is positive for China and Russia. Although it is relatively weak, 
Russia’s sovereign CDSs depict a relatively stronger association with currency volatility than all countries across BRICS, while South Africa’s sovereign CDSs are the least affected by currency volatility.

\subsection{Analysis of empirical results: Tail dependence structures for BRICS countries Pairwise tail dependence of risk factors and sovereign CDS}

This section breaks down the dependency structure between sovereign CDSs and a suite of global risk factors based on vine-copulas which are used to decompose implicit dependence structure from empirical data. Copulas are used to assess dependence structure to overcome the overly restrictive assumption of normality in the distribution of marginals, which compromises the legitimacy and accuracy inferences drawn based on simple Spearman correlation measure. Given that BRICS data is not normally distributed (J-B normality test with p-values of 0.00), we used VineCopula package to determine the underlying distribution type and identify optimal copula type that fits each bivariate combination of sovereign CDS and global risk factors. The best-fit copula type was chosen based on the AIC criteria and then fitted onto the bivariate combinations to extract the true rank dependent measure of association, with the results summarised in Table $\mathrm{C}$ below for further discussion on the next page.

Table C: Dependency structure of sovereign CDS and global risk factors in BRICS

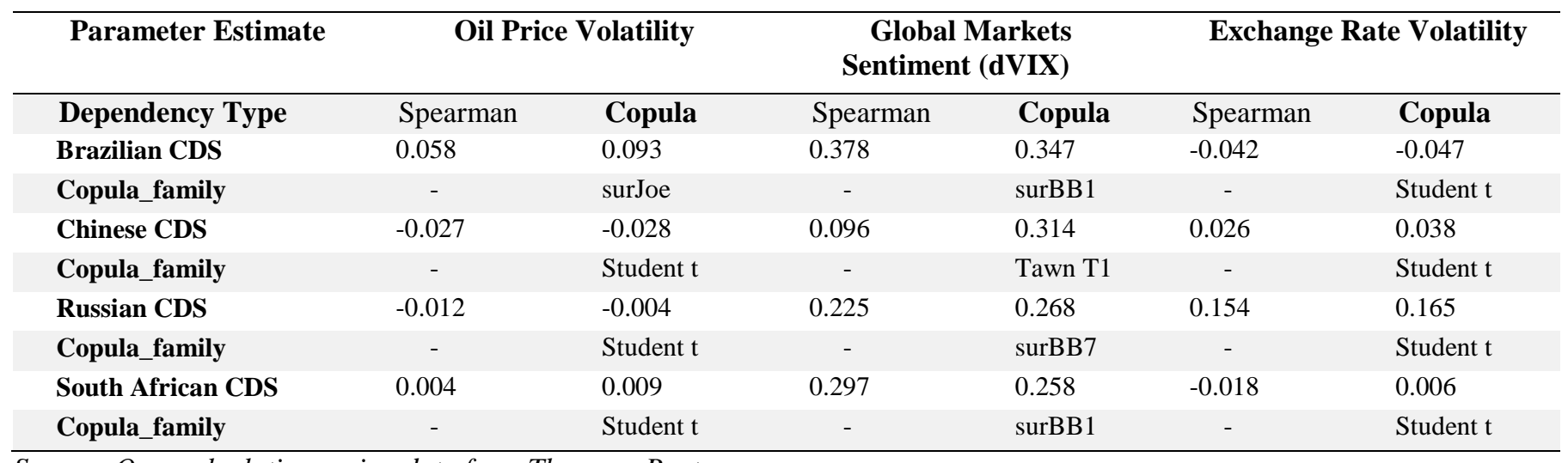

Source: Own calculations using data from Thomson Reuters

The direction of association estimated by optimal copulas and linear correlation measure is consistent, both confirming positive or negative co-movements of bivariate combinations as student-t copula is the most common and it exhibits elliptical properties while accounting for tail dependence. However, the strength of copulas dependency structure is more robust and accurate as it incorporates the empirical marginal distribution of each variable in the bivariate copula process, thereby overcoming the restrictive presumption of normal distribution of marginals under the Spearman correlation measure. However, South 
African CDS spreads and exchange rate risk presents an exceptional case where dependency structure changes from negative (Spearman correlation) to positive under copula measure but remains negligible.

Furthermore, the most valuable exposition from bivariate copulas is the reaffirmation of J-B normality test confirming that the underlying empirical marginal distributions are not normal for all variables. However, there is sufficient evidence of symmetry between exchange rate volatility and sovereign CDSs across all BRICS countries as confirmed by student-t copula selection as the most optimal copula type to fit the empirical data. From an empirical perspective, the most optimal copula type is student t copula for Oil price risk and sovereign CDSs, signifying the existence of symmetrical impact of oil volatility on sovereign credit risk for China, Russia, and South Africa.

Brazil presents a unique case where the optimal copula type is survival Joe copula which captures asymmetrical effects and extreme tail observations in the empirical data. Most importantly, the dependency strength reduces (whether positive or negative under Spearman correlation) lower strength under copula measure but remains very small except for Brazil where there was an increase from 5.8\% to 9.3\% when the empirical marginal distributions are used in the correlation analysis. The optimal copula family for sovereign CDSs and exchange rate volatility is confirmed as Student-t copula across all countries, suggesting symmetry and this is consistent with expectations documented in existing literature. For the global risk sentiment, optimal copula is survival type (Joe-Clayton/Gumbel) to Tawn type copulas which are asymmetrical and considers tail observations and this variable have the strongest (and positive) association with sovereign CDS spreads of BRICS than any other global risk factor under consideration in this study.

\section{Comparison of tail dependence structures within and across BRICS countries}

There is overwhelming empirical evidence that global market sentiment is a crucial positive driver of sovereign CDS spreads in BRICS. Brazil has the highest positive correlation (38\%) followed by China (31\%), Russia (27\%) and South Africa (26\%), implying that Brazil’s sovereign CDSs are more vulnerable to global risk sentiment while South Africa is the least impacted across BRICS. This positive dependency is expected for emerging markets economies that are generally characterised by higher yield sovereign bonds and liberalised financial markets which offer international investors seamless access to local financial markets to facilitate portfolio investments and foreign direct investment flows. Therefore, these countries must consider financial sector regulations that mitigate major risks that accompany the 
globalisation of access to local financial markets to proactively manage the impact on the country's credit risk profile, which ultimately affects costs of borrowing and fiscal debt service costs.

Furthermore, oil price risk is the second biggest driver of sovereign CDS spreads for Brazil (9.3\%) and South Africa (0.9\%) while exchange rate risk exhibits a very small contribution to changes in sovereign CDS spreads. On the contrary, exchange rate risk is the second-largest influential factor for China (3.8\%) and Russia’s (16.5\%) sovereign CDS spreads while oil price volatility contributes the lowest $2.8 \%$ and $0.4 \%$, respectively. The massive cross-country variation is largely driven by different exchange rate regimes adopted by each respective country (e.g., China operates under a pegged currency system while other economies are on flexible exchange rate regimes) and China's position as the largest oil consumer in the world plays a sizable role. Russia's exposure to oil price volatility is the least significant factor to sovereign CDS spreads as oil price hedging positions alleviate potential oil revenue volatility from currency fluctuations and its position as a net exporter provides benefit from prepaid orders.

The dependency structure of CDS/exchange rate risk and CDS/oil price volatility also differ significantly within each country, where one risk factor largely dominates at a massive scale, such as Russia where exchange rate risk scores a dependence of $16.5 \%$, which is highly dominant compared to oil price risk with a dependence of $-0.4 \%$. Similar observations hold for Brazil where the CDS/oil price volatility strength stands at 9.3\% compared to CDS/currency risk correlation strength of $4.7 \%$. Finally, China exhibits a CDS/ currency volatility dependence of 3.8\% compared to CDS association to oil price risk of $-2.8 \%$. This finding is very crucial for Russia to consider in financial sector policy formulation, where it is important to introduce policy measures to mitigate the large impact of currency volatility on the fiscal oil revenues, given that an increase in currency risk leads to an increase in sovereign CDS Spreads. The oil price risk remains well contained through existing hedging arrangements, ultimately resulting in negligible impact on CDS spreads.

Brazil and China's cases are slightly different, the scale dominance effect is very moderate compared to Russia, implying that Brazil and China cannot exclusively regulate or proactively manage spillovers from one risk factor to mitigate overall spill-over risks on sovereign CDS spreads, ultimately the sovereign credit risk profile. On the contrary, South African dependency structure is unique, empirical evidence points to only global risk sentiment (26\%) as the single largest driver of sovereign credit risk while exchange rate risk and oil price volatility have negligible dependence with the sovereign CDS spreads. 


\section{Conclusion}

The study examined the tail dependency structure of sovereign credit risk and each of three selected global risk factors for the BRICS community using copulas approach, which is known for its ability to provide the "true" tail correlation based on the correct marginal distribution. The empirical results show that global market risk sentiment is very crucial in driving sovereign CDS spreads in the BRICS countries under extreme market events, with Brazil having the highest co-dependency followed by China, Russia, and South Africa. This dependency is expected for emerging markets that are generally characterised by higher-yield sovereign bonds and internationally liberalised financial markets which offer foreign institutional investors seamless access to local markets to facilitate portfolio investments and foreign direct investment flows. Therefore, it is critical for BRICS policymakers to consider financial sector regulations that mitigate spill-over risks such as capital controls under distressed markets, to maintain financial system stability, which can arise from unrestricted access to local financial markets by risk-averse foreign investors. Such policy can proactively manage the impact of global sentiment on the country's credit risk profile, which ultimately affects the cost of borrowing and fiscal debt service costs.

Furthermore, oil price volatility is the second biggest risk factor correlated with sovereign CDS spreads for Brazil and South Africa while exchange rate risk exhibits very small co-movements to changes in sovereign CDS spreads, under extreme market conditions dominated by tail events. On the contrary, exchange rate risk is the second largest risk factor associated with China and Russia's sovereign CDS spreads while oil price volatility exhibits the lowest association to CDS in these countries. Between oil price and currency risk, evidence of single risk factor dominance is found for Russia where exchange rate risk is largely dominant (second to global sentiment), implying that Russia can mitigate or manage spillover effects on sovereign CDS spreads by enacting financial sector regulations that mitigate exchange rate risk. 


\section{Suppelementary materials}

Data in Excel sheet and R codes used for this research are made available as supplementary files.

\section{Author Contributions.}

Conceptualization, BD Simo-Kengne and P Rikhotso; Methodology, BD Simo-Kengne and P Rikhotso; Software, P Rikhotso.; Validation, BD Simo-Kengne; Formal Analysis, BD Simo-Kengne and P Rikhotso; Investigation, P Rikhotso; Resources, BD Simo-Kengne and P Rikhotso; Data Curation, P Rikhotso; Writing - Original Draft Preparation, P Rikhotso; Writing - Review\& Editing, BD Simo-Kengne and P Rikhotso; Visualization, BD Simo-Kengne and P Rikhotso; Supervision, BD Simo-Kengne; Project Administration, BD Simo-Kengne; Funding Acquisition, not applicable.

\section{Data Availability Statement.}

Data used for this research is submitted as supplementary files, including the R script used for the estimation.

\section{Conflicts of Interest.}

The authors declare no conflict of interest. 


\section{References}

Aas, K. (2004). Modelling the dependence structure of financial assets: A survey of four copulas. Norwegian Computing Center, (4): 22 - 30.

Akaike, H. (1973). Information theory and an extension of the maximum likelihood principle. In B. N. Petrov, \& F. Csaki, Proceedings of the Second International Symposium on Information Theory Budapest (pp. 267 - 281). Akademiai Kiado.

Augustin, P., Chernov, M., \& Song, D. (2020). Sovereign credit risk and exchange rates: Evidnce from CDS quanto spreads. Journal of Financial Economics, (137): 129 - 151.

Ballester, L., \& Gonzalez-Urteaga. (2020). Is there a connection between Sovereign CDS spreads and the stock market? Evidence for European and US Returns and Volatilities. Mathematics, 1667.

Barberis, N., Shleifer, A., \& Wurgler, J. (2002). Comovement theory. Chicago: Harvard University.

Blommestein, H., Eijffinger, S., \& Qian, Z. (2016). Regime-dependent determinants of Euro area sovereign CDS spreads. Journal of Financial Stability, (22): 10 -21.

Blum, P., Dias, A., \& Embrechts, P. (2002). The art of dependence modelling: The latest advances in correlation analysis. In Alternative Risk Strategies. London: Risk Books.

Boubaker, H., \& Sghaier, N. (2013). Portfolio optimization in the presence of dependent financial returns with long memory: A copula-based approach. Journal of Banking \& Finance, 361-377.

Bouye, E., Durrlemann, V., Nikeghbali, A., Riboulet, Q., \& Roncalli, T. (2000). Copulas for finance - a reading guide and some applications. Technical report, Credit Lyonnais.

Brechmann, E. C. (2010). Truncated and simplified regular vines and their applications. Technische Universitaet Muenchen.

Embrechts, P., Lindskog, F., \& McNeil, A. J. (2003). Modelling dependence with copulas and applications to risk management. In S. T. Rachev, Handbook of Heavy-tailed Distributuions in Finance. North-Holland: Elsevier.

CIA Factbook., (2021). https://data.worldbank.org/indicator/BX.KLT.DINV.CD.WD?end=2019\&locations=BR-RU-

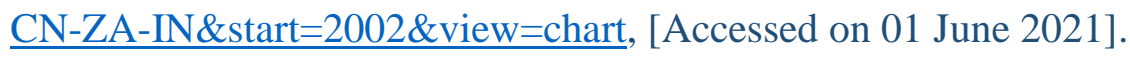


Embrechts, P., McNeil, A. J., \& Straumann, D. (2001). Correlation and dependency in risk management: Properties and pitfalls. In Value at Risk and Beyond. Cambridge University Press.

Fermanian, J.-D., \& Scaillet, O. (2002). Non-parametric estimation of copulas for time series. Journal of Risk, (4): 25 - 54.

Galariotis, E. C., Makrichoriti, P., \& Spyroub, S. (2016). Sovereign CDS spread determinants and spillover effects during financial crisis: A panel VAR approach. Journal of Financial Stability, (26): 62-77.

Grammatikos, T., \& Vermeulen, R. (2012). Transmission of the financial and sovereign debt crises to the EMU: Stock prices, CDS spreads and exchange rates. Journal of International Money and Finance, (31): 517 - 533.

Hair, J. F., Hult, G. T., Ringle, C. M., \& Sarstedt, M. (2017). A primer on Partial Least Squares Sctructural Equation Modelling (PLS - SEM). Thousand Oaks, CA: Sage.

Longin, F., \& Solnik, B. (2001). Extreme correlation of international equity markets. The Journal of Finance, 56(2): 649 - 676.

Manner, H. (2007). Estimation and model selection of copulas with an application to exchange rates. Maastricht University: METEOR Research memorandum.

McNeil, A., Frey, R., \& Embrechts, P. (2002). Extreme co-movements between financial assets. Technical report, Columbia University.

Tabak, B. M., Miranda, R. C., \& Medeiros Jr, M. D. (2016). Contagion in CDS, banking and equity markets. Economic Systems, (40): 120 - 134.

Wang, A. T., Yang, S.-Y., \& Yang, N.-T. (2013). Information transmission between sovereign debt CDS and other financial factors - The case of Latin America. North American Journal of Economics and Finance, (26): 586 - 601.

Worldbank., (2021).

https://data.worldbank.org/indicator/BX.KLT.DINV.CD.WD?end=2019\&locations=BR-RU-

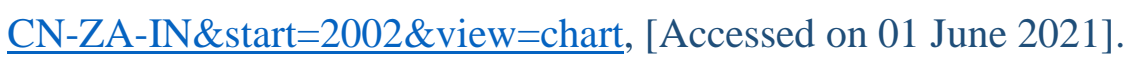


Yang, L., Yang, L., \& Hamori, S. (2018). Determinants of dependence structures of sovereign credit default swap spreads between G7 and BRICS countries. International Review of Financial Analysis, (59): 19-34.

Appendices and tables

Figure 2(a): External Account Balance

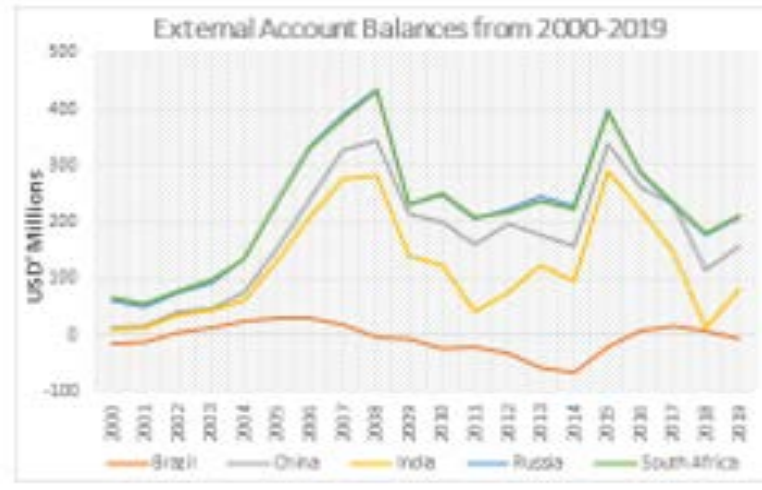

Figure 2(c): Interest Rate Spreads

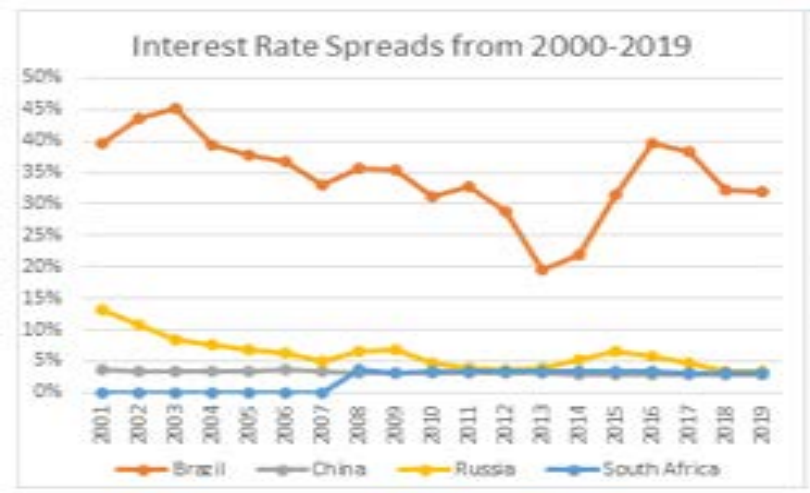

Figure 2(b): Net Portfolio Investment Inflows - Bonds

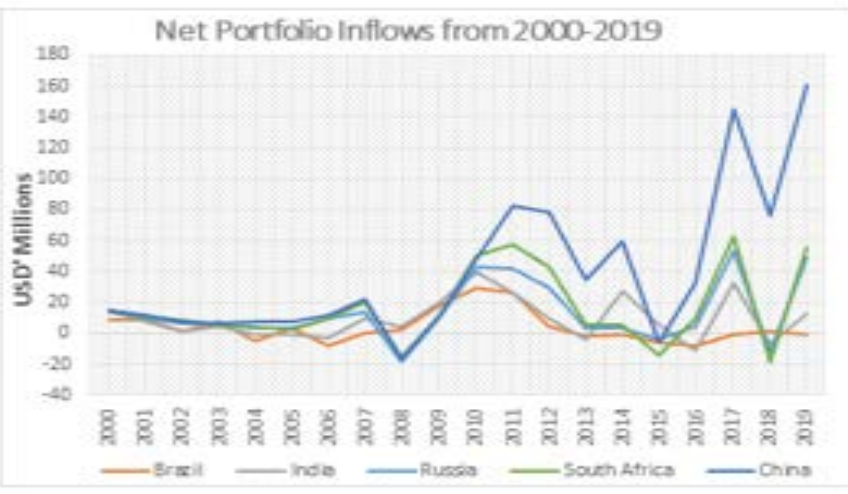

Figure 2(d): Foreign Direct Investment Inflows (USD'bn)

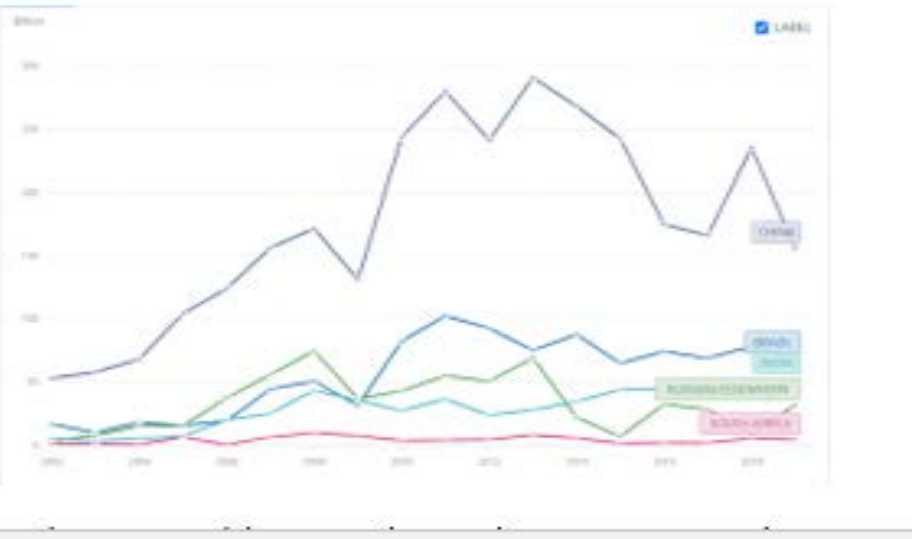


Figure 3: Overview of BRICS sovereign CDS spreads, oil price, exchange rate and global volatility (VIX) Volatility of index level series
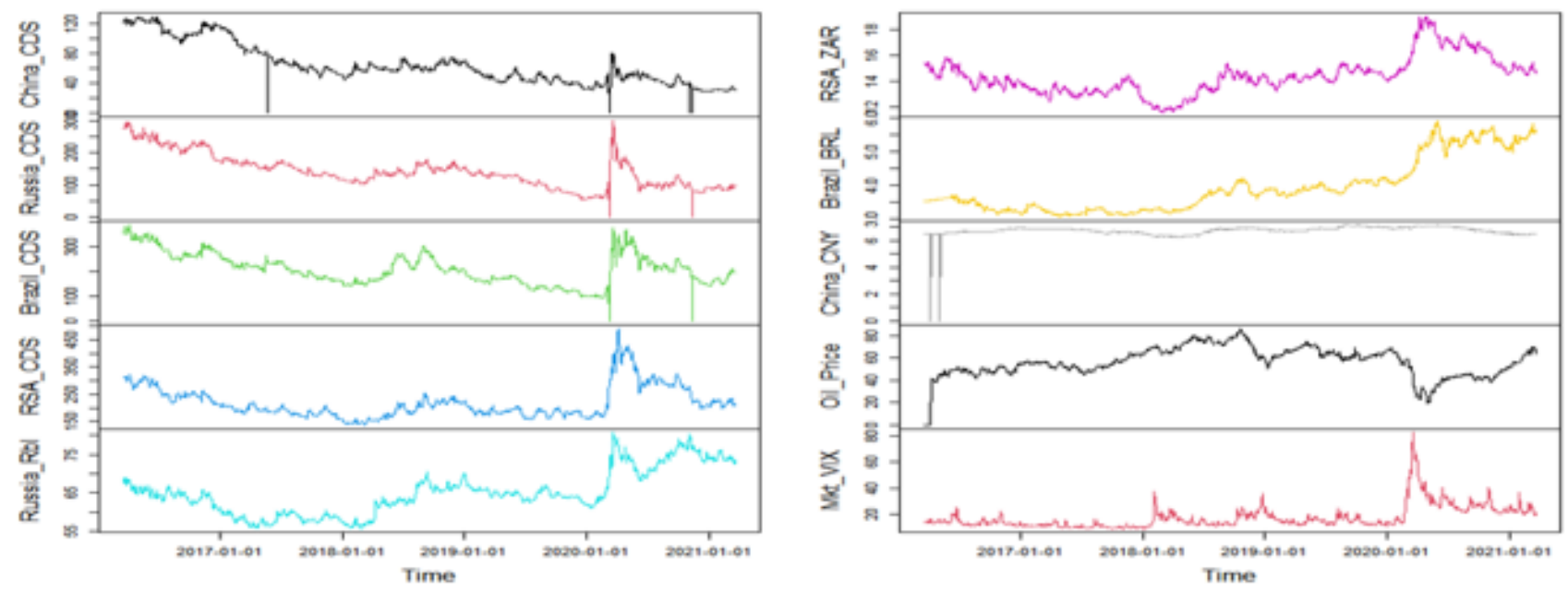

Figure 4: Volatility of returns series, reflecting recursive volatility clusters.
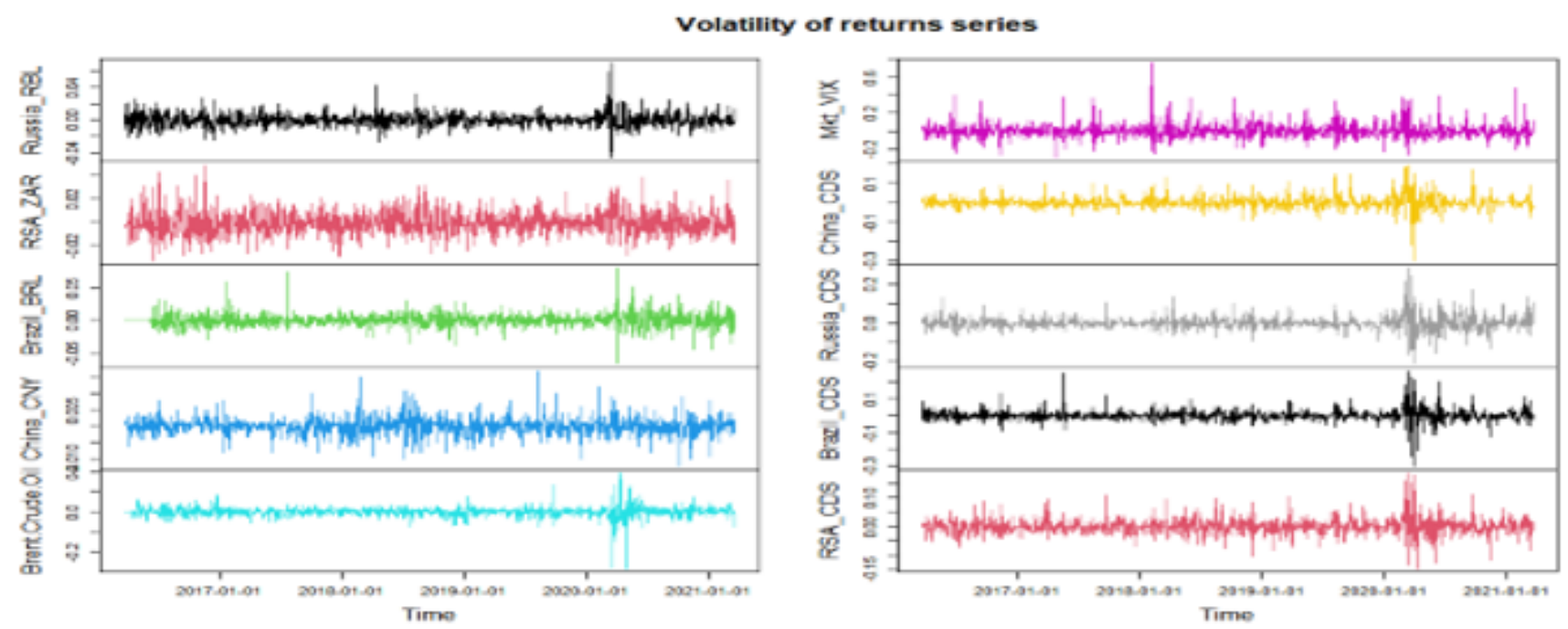